\title{
MIGUEL BARNET \\ Y LA NOVELA-TESTIMONIO *
}

\author{
POR \\ ELZBIETA SKLODOWSKA \\ Universidad de Varsovia
}

Miguel BARNET: POESÍA, ETNOLOGÍA, NOVELA TESTIMONIAL

La obra de Miguel Barnet (n. 1940) se inscribe en su integridad en el marco de la literatura cubana de la Revolución. Barnet se dio a conocer primero como poeta a través de los tomos La piedrafina y el pavorreal (1963) y La isla de güijes (1964), cuya forma sencilla, pero profundamente lírica, fue influida por los mitos, la imaginería y la sintaxis popular afrocubana. Estos versos ostentaban ya una característica que iba a marcar la obra ulterior del escritor con un signo inconfundible y original: una hábil conjugación de la poesía y la etnología con el lenguaje «conversacional». La aparición de la Biografía de un cimarrón (1966) — seguida por una inmediata aclamación crítica y una difusión en varios países del mundoconsagró a Barnet como pionero de la novela testimonial hispanoamericana ${ }^{1}$. Su consistencia en el empleo del testimonio (Canción de Rachel, 1969; Gallego, 1981; La vida real, 1986) y su contribución teórica a la definición de esta forma le han convertido en el exponente más importante de la veta testimonial en el contexto hispanoamericano y uno de los escritores más destacados de la literatura cubana contemporánea.

Aunque el reconocimiento de la crítica y el éxito con los lectores se debe, sobre todo, a su narrativa testimonial, Barnet no ha renunciado ni a la poesía ni a la etnología: en 1978 publicó una recopilación de fábulas

* La realización del presente ensayo ha sido posible gracias al apoyo de Mellon Postdoctoral Fellowship de la University of Pittsburgh.

' Barnet no se considera precursor de esta tendencia y señala la influencia que han tenido sobre su obra autores como Ricardo Pozas Arciniegas, Oscar Lewis y la nonfiction norteamericana de Truman Capote y Norman Mailer. 
afrocubanas: Akeké y la jutía, en 1980 dio a conocer el pequeño volumen Orikis y otros poemas y en 1983 una colección de ensayos, La fuente viva. En vez de tratar la poesía, la etnología y la narrativa como distintas formas de expresión, Barnet ha experimentado con ellas en cuanto estrategias complementarias en su tarea de aprehensión e interpretación de la cultura cubana. El mismo ha comentado así su aparente eclecticismo, que le permite salirse de los esquemas: «Creo que a mí me definió muy bien, en la reunión de LASA, Jorge Domínguez, diciendo que yo era un "todólogo". Yo lo que realmente soy es un atrevido. Yo pienso que un escritor debe escribir de todo» ${ }^{2}$.

Aunque las novelas testimoniales de Barnet han sido difundidas en todo el mundo hispanohablante y ampliamente traducidas y sus ensayos vuelven a ser glosados y reeditados ${ }^{3}$, la bibliografía sobre su obra sigue siendo relativamente reducida. Es evidente el predominio de reseñas y entrevistas, mientras que son escasos los estudios analíticos y síntesis de la trayectoria literaria barnetiana ${ }^{4}$. En los últimos años, el interés crítico por la creación testimonial ha aumentado, pero el enfoque ha sido más bien sistematizador y la obra del cubano ha merecido tan sólo menciones tangenciales en estudios de carácter más general ${ }^{5}$. En el presente artículo nos proponemos, por tanto, discutir las diferentes facetas de la creación de Barnet —etnólogo, poeta, narrador, ensayista-, haciendo hincapié en su fundamental aportación teórica y estética a la formación y evolución de la novela testimonial hispanoamericana.

${ }^{2}$ Emilio Bejel, «Entrevista con Miguel Barnet», Hispanoamérica, vol. 10, núm. 29, 1981, p. 46.

${ }^{3}$ Miguel Barnet, «La novela-testimonio: socio-literatura», Unión, núm. 4 (1969). También en su recopilación de ensayos, La fuente viva (La Habana, 1983), pp. 12-42; en la misma selección, también «Testimonio y comunicación: una vía hacia la identidad», páginas 43-60. El ensayo seminal de Barnet fue reproducido también como «The documentary novel», en Cuban Studies/Estudios Cubanos, vol. 11, núm. 1 (1981), pp. 19-32.

${ }^{4}$ Roberto González Echevarría, "Biografía de un cimarrón and the Novel of the Cuban Revolution», Novel. A Forum on Fiction, vol. 13, núm. 3 (Spring, 1980), pp. 249-263; Raquel Chang-Rodríguez, «Sobre La canción de Rachel, novela-testimonio», Revista Iberoamericana, vol. 44, núms. 102-103 (1978), pp. 133-138; Elzbieta Sklodowska, «Biografía de un cimarrón, de Miguel Barnet: revisión de la historia afrocubana», Historiografía y Bibliográfía Americanistas, vol. XXVII (1983), pp. 43-59.

${ }^{5}$ Carlos Rincón, El cambio de la noción de la literatura y otros ensayos (Bogotá: Instituto Colombiano de Cultura, 1978); John Beverly, «Anatomía del testimonio», en su Del Lazarillo al Sandinismo: Estudios sobre la función ideológica de la literatura española e hispanoamekicana (Minneapolis, 1987), pp. 153-168; Josaphat Bekunuru Kubayanda, «Minority Discotrse and the African Collective: Some Examples from Latin American and Caribbean Literałure», Cultural Critique, núm. 6 (Spring, 1987), pp. 113-130; René Jara y Hernán Vidal (eds.), Testimonio y literatura (Minneapolis, 1986). 
DESDE LA ETNOLOGÍA HACIA LA NOVELA: EL CASO DE LA BIOGRAFIA DE UN CIMARROON

Si entendemos la novela, tal como lo sugiere Bajtin, en cuanto una forma literaria heterogénea y proteica, en trance de formación, y a la vez la más apta para apropiarse del contexto histórico (chronotope), la clasificación de la Biografía de un cimarrón en el marco del género novelesco será perfectamente justificada. La palabra «testimonio» —empleada por Barnet en sus ensayos - cumple una función modificadora, señalando solamente la intención autorial, sin hablar del contenido (novela histórica, psicológica, etc.), ni de la técnica narrativa (novela realista, fantástica, etcétera).

En varias ocasiones se han señalado los vínculos de la Biografía con la tradición picaresca, reparando sobre todo en las características del protagonista-narrador (su marginalidad y calidad de antihéroe, su humorismo plebeyo). Curiosamente, también la estructura de la Biografía corresponde al esquema que Antonio Gómez-Moriana propuso en su análisis del Lazarillo de Tormes: al discurso prologal (metadiscurso) le sigue el relato de la vida, en que predomina el pretérito, con «digresiones en que la alternancia pasado/presente muestra actitudes cambiantes en el proceso de toma de conciencia del sujeto enunciador» ${ }^{6}$. Es importante notar, sin embargo, que el metadiscurso inicial sobre las circunstancias y el objetivo de la creación del texto está, en el caso de la novela testimonial, a cargo del «gestor» del testimonio. Barnet se ha valido, pues, de una práctica narrativa que podemos llamar — casi de manera oximorónica- «discurso autobiográfico mediatizado».

Si nos atenemos al esquema de comunicación que Gómez-Moriana ofrece para el Lazarillo, también en la Biografía vamos a discernir el desdoblamiento del autor en «presentador» (Barnet en cuanto autor de introducción, notas, glosario, montaje, títulos de capítulos) y «narrador» (Montejo en cuanto autor de la historia de su vida) ${ }^{7}$. El mismo esquema nos permite percibir más claramente la potencial discrepancia en las intenciones de los dos «autores»: mientras que para Montejo el destinatario de su «confesión» es el «editor», éste, a su vez, se propone dirigir el texto a un círculo más amplio de lectores, con el objetivo de testimoniar y reivindicar. En el caso de la Biografía, la autoconciencia reivindicadora de Montejo permite un acercamiento entre las dos encarnaciones del «autor».

\footnotetext{
${ }^{6}$ Antonio Gómez-Moriana, «La subversión del discurso ritual-II», Co-Textes, núm. 8 (diciembre 1984); p. 60.

7 Antonio Gómez-Moriana, «Autobiografía y discurso ritual», Co-Textes, núm. 8 (diciembre 1984), p. 92
} 
Consideramos imposible, sin embargo, una fusión perfecta entre los dos, aunque Barnet la plantea como real: «En este caso yo digo y mantengo que he sido fiel a las historias de Rachel y de Esteban (...). He podido penetrarlos. He podido identificarme con ellos, con sus problemas, con sus angustias (...). Es una sensación verdaderamente tremenda. Ser otro y ser tú mismo. Convertirte en una imagen» ${ }^{8}$.

En la obra de Barnet, la mediación entre el discurso autobiográfico y el testimonial proviene de la práctica discursiva no-literaria, o sea, de la entrevista etnológica. Sus ensayos tienden a demostrar la posibilidad de una armoniosa conciliación de estas dos formas discursivas (la literaria y la científica) y de dos sensibilidades distintas a través del uso de estrategias y capacidades específicas: la eliminación del ego del escritor, una excelente comunicación con el entrevistado, el conocimiento de la época y la natural habilidad del editor para captar las sutilezas del habla ${ }^{9}$.

El discípulo de Fernando Ortiz, y lector aficionado de los libros de Oscar Lewis, pareció haberse dado cuenta de que la preservación de valores ignorados y casi extintos de la cultura afrocubana sería posible tan sólo a través de los medios ajenos a esta cultura (la grabación, la escritura, el discurso culto europeo), mientras que su sensibilidad poética le ayudaría a minimalizar el riesgo de la «traición» con respecto al discurso original del «otro». En su introducción a la Biografía, al igual que en sus ensayos y entrevistas, Barnet no se propone suministrar «recetas» ni definiciones del testimonio, intentando resolver los problemas formales e ideológicos en la práctica de la escritura.

El hecho de que la Biografía de un cimarrón - aunque publicada por el Instituto de Etnología y Folklore- haya sido leída como novela, se debe a una conjunción particular de circunstancias. El encuentro entre el joven investigador y el anciano residente en el Hogar de Veteranos, Esteban Montejo, no hubiera desembocado en un discurso de alto valor cognoscitivo, estético y humano si no fuera por el don narrativo de Montejo y su sentido del humor, su personalidad pintoresca y su memoria lúcida. La intervención editorial de Barnet, a su vez, ha otorgado a las rememoraciones del ex cimarrón el necesario ritmo dramatúrgico y la secuencia cronológica (la esclavitud, el cimarronaje, la Guerra de la Independencia, la guerra racial cubana de 1912). La proverbial «sequedad» del documento científico ha sido contrarrestada por la personalidad de Montejo y el respeto de Barnet por las vivencias íntimas de su interlocutor. Comenta al respecto

\footnotetext{
${ }^{8}$ Emilio Bejel, op. cit., p. 49.

- Cf. los ensayos citados de Barnet, su entrevista con Bejel, al igual que «Miguel Barnet charla con los editores de Vórtice», Vórtice, vol. 2, núms. 2-3 (verano 1979), pp. 1-10; también la entrevista por Luis Iñigo Madrigal, Araucaria, núm. 25 (1984), pp. 116-123.
} 
Moreno Fraginals: «Todo esto va acompañado de centenares de observaciones minúsculas, increíbles, sobre una hoja, una mujer, un juego, un vestido, un dulce, el aburrimiento de los barracones en tiempo muerto, los curas, los velorios, los bandoleros... ${ }^{10}$. Los detalles aparentemente insignificantes, diluidos o ignorados en las obras de la «gran» historiografía, adquieren en la novela testimonial su valor humano, que — siguiendo a Unamuno- podríamos denominar «intrahistórico».

La originalidad del proyecto barnetiano consiste, pues, en su atrevido eclecticismo formal. De un discurso científico el escritor toma prestado el método de recopilación del material (entrevista, grabación, fichas, investigación de la época), pero en la organización del mismo no ignora los criterios estéticos (selección, condensación, montaje, línea dramatúrgica). En uno de los comentarios más perspicaces sobre la Biografía, Manuel Moreno Fraginals nos dice: «La primera característica que sorprende en la Biografía de un cimarrón es el respeto y el amor con que ha sido escrito. Barnet no ha pretendido en forma alguna hacer literatura, aunque haya logrado una de las más acabadas obras literarias cubanas del siglo. La belleza extraordinaria del libro, la fuerza de vida captada, está precisamente en esa honestidad. Esto sólo podía lograrlo quien reuniera las dotes de investigador $\mathrm{y}$ de poeta» ${ }^{11}$.

\section{EL VALOR REIVINDICADOR DE LA NOVELA TESTIMONIAL}

Nos parece importante que la propuesta de Barnet —entendida como la reivindicación de la gente sin historia- se considere no solamente dentro del marco de la literatura cubana e hispanoamericana, sino en el contexto más amplio del mundo poscolonial, donde abundan los proyectos - a veces ideológicamente dispares- concebidos con el objetivo de crear medios de expresión para las conciencias marginadas. Para Latinoamérica $-\mathrm{y}$, sobre todo, para el Caribe- es fundamental en este aspecto la precursora obra de Frantz Fanon, que plantea la necesidad de un contradiscurso dirigido a liberar la conciencia del colonizado (negro, esclavo, Calibán) de su existencia enajenada e inauténtica dentro de los paradigmas de la cultura colonizadora ${ }^{12}$. Los revolucionarios cambios sociales en Cuba han creado condiciones excepcionalmente favorables para la autorreivindicación de

${ }^{10}$ Manuel Moreno Fraginals, «Biografía de un cimarrón» (reseña), Casa de las Américas, núm. 140 (1987), p. 132.

11 Ibid.

12 Cf. Benita Parry, «Problems in Current Theories of Colonial Discourse», The Oxford Literary Review, vol. 9 (1987), pp. 27-58. 
los marginados, pero el papel mediador del intelectual ha mantenido su vigencia debido a los vestigios de la superestructura anterior y la falta de autoconciencia testimonial por parte de los representantes de la gente sin historia.

En la América mestiza y mulata, el intelectual hispanohablante de formación europea tiene que plantearse la pregunta fundamental: ¿cómo estudiar la cultura india o afroamericana evitando una perspectiva manipulativa y represiva? Esta cuestión viene inscrita en la experimentación lingüística de la literatura indigenista (José María Arguedas, Augusto Roa Bastos), en la evolución expresiva de la poesía afroamericana (Nicolás Guillén) y precisamente en la novela testimonial de los años sesenta y setenta (Barnet, Poniatowska, Burgos Debray) ${ }^{13}$.

Los recientes trabajos críticos de Gayatri Spivak insisten en la inexorable traición y manipulación del subalterno por parte del agente europeo y en la subsiguiente «colaboración» del nativo en la formación de su imagen en cuanto «el otro» y privado de la palabra ${ }^{14}$. Aunque no pretendemos negar la presencia mediadora del editor, en el caso de la Biografía de un cimarrón la personalidad de Esteban Montejo no está sometida a una cosificación tan propia de las visiones «folklóricas» del negro o, más aún, de la literatura antiesclavista decimonónica. El rebelde eterno, el hijo de manigua - según se denomina él mismo-, Esteban Montejo, cobra su presencia, ya no literaria, sino humana, precisamente gracias a su espíritu de cimarronaje y la integridad de su sistema de valores y creencias. Inseguro de su origen, de su apellido, de su fecha de nacimiento, pero siempre dispuesto a luchar por su libertad y dignidad, Montejo se niega a rendirse inclusive al borde de la muerte: «Por eso digo que no quiero morirme, para echar todas las batallas que vengan» ${ }^{15}$. El que habla aquí no es un subalterno pasivo, sino un hombre consciente de sus derechos y de las injusticias que se han infligido a su raza, capaz de denunciarlas, además, con su increíble poder de rememoración: "Ahí hay muchos terrenos que investigar. Yo estoy seguro que el día cuando se descubra toda la maraña que hay oculta, se va a acabar el mundo» (p. 209).

El extraordinario éxito de la Biografía de un cimarrón ${ }^{16}$ parece haber

${ }^{13}$ Nos referimos a las novelas testimoniales de Elena Poniatowska Hasta no verte Jesús mío (México, 1968) y Rigoberta Menchú/Elizabeth Burgos, Me llamo Rigoberta Menchú y así me nació la conciencia (México, 1985).

${ }^{14}$ Gayatri Spivak, «Can the Subaltern Speak?», Marxist Interpretations of Culture (Urbana, 1987)

15 Miguel Barnet, Biografía de un cimarrón (La Habana: Instituto de Etnología y Folklore, Academia de Ciencias de Cuba, 1966), p. 208.

${ }^{16}$ En la entrevista con Emilio Berjel, Barnet habla de las numerosas adaptaciones de radio, cine y teatro que se han hecho de la historia del cimarrón en Cuba y los Estados Unidos. 
alentado a Barnet a proseguir el objetivo que se había propuesto ya en sus primeros poemarios y durante su trabajo de investigación etnológica en la Academia de Ciencias: la búsqueda de la identidad cultural cubana a través de sus manifestaciones ignoradas o marginales. No obstante, la recreación del pasado a través de los «individuales momentos psíquicos», según dijera Lévi-Strauss, adquiere en la obra de Miguel Barnet características de una visión sintética y más objetiva de lo que pudiera parecer, ya que hay una continuidad de temas, motivos y episodios históricos entre sus sucesivas novelas y una subyacente tendencia a hilvanar los hechos desde la perspectiva de la lucha de clases.

\section{CANCION DE RACHEL Y GALLEGO:}

CONTINUIDAD Y RUPTURA EN LA PRÁCTICA TESTIMONIAL DE BARNET

En 1967, Barnet publicó una colección de poemas, La sagrada familia, que recibió mención en el concurso de Casa de las Américas y llegó a confirmar su dominio de la forma lírica y su interés por la realidad más inmediata en todo su dinamismo humano y conflictividad socio-histórica. En 1969, dio a conocer Canción de Rachel, una obra narrativa que - aunque denominada «novela testimonial»- se acerca más a una novela autorial ${ }^{17}$. Barnet empleas varias técnicas de beletrización (collage de recortes de prensa, multiperspectivismo, recreación de diálogos) y llega a recrear la identidad de seis actrices entrevistadas, fundiéndolas en la figura literaria de Rachel. La «canción» sustituye a la «biografía», una protagonista ficticia a un personaje de carne y hueso, una narradora no fidedigna a la «voz de la verdad».

En su segunda novela, Barnet persigue una síntesis socio-política de la época republicana a través de los chismes, anécdotas y acontecimientos de la petite histoire, a la vez que subraya la continuidad histórica y temática con respecto a la Biografía. Valiéndose de un diálogo intratextual, el autor hace aparecer a Esteban Montejo en el coro de voces que desmienten el discurso de la estrella del teatro "Alhambra». Los prejuicios racistas de Rachel están contrarrestados por las palabras siguientes: «Al menos, el que venga adonde estoy yo a decirme que si el racismo, que si los negros eran sanguinarios, le voy a dar un soplamocos que va a saber quién es Esteban Montejo» ${ }^{18}$.

Un procedimiento intratextual semejante aparece en la novela testimo-

\footnotetext{
17 John Beverley, op. cit., p. 167.

${ }^{18}$ Miguel Barnet, Canción. de Rachel (Buenos Aires: Ed. Galerna, 1969), p. 79.
} 
nial de 1981, Gallego, donde Barnet hace a su protagonista evocar el mundillo de las coristas del «Alhambra», aunque esta vez se sale de nombres auténticos: «Yo las recuerdo a todas: Luz Gil, Amalia Sorg, Blanca Becerra» ${ }^{19}$. Gallego parece combinar la aspiración etnológica de la Biografía (notas aclaratorias, la autoridad del protagonista para con sus propias vivencias) con el afán «tipificador» de una novela realista que, según Lukács, lograba su representatividad a través de la selección y síntesis. La configuración del protagonista en cuanto «sujeto colectivo individual» lukacsiano está señalada por Barnet en la breve introducción a la novela: «En esta historia, Manuel Ruiz, que, como dije, puede llamarse Antonio, Fabián o José, es por encima de todo Manuel Ruiz, el Gallego».

Aunque, en comparación con la primera novela, la presencia autorial está más marcada en Canción de Rachel y en Gallego, el método de la entrevista sigue siendo el recurso principal de mediatización entre el discurso oral autobiográfico y el texto novelesco-testimonial. Este procedimiento implica una íntima interacción verbal entre dos sujetos y su «mutua autoiluminación» ${ }^{20}$. La riqueza de las novelas barnetianas se funda en la recreación «amorosa» de estilos inconfundibles de sus narradores: desde el lenguaje metafórico de Montejo, a través del habla urbana de Rachel, hasta el discurso nostálgico de Manuel Ruiz, quien intenta fundir su sensibilidad gallega y rural con el idioma de su patria adoptiva.

Si consideramos las novelas de Barnet como una parte del proyecto más vasto de autodefinición cultural, esta polifonía lingüística puede interpretarse como reflejo de la complejidad dinámica de la cultura cubana. En su definición de la polifonía, dice Pierette Malcuzynski, siguiendo a Bajtin: «El objetivo artístico de la polifonía es demostrar la coexistencia, interacción e interdependencia de conciencias diferentes y relativamente autónomas que expresan simultáneamente varios contenidos del mundo en el marco de un texto dado» ${ }^{21}$. Al subrayar precisamente la interacción de voces distintas en el marco intratextual de su novelística, Barnet parece oponerse tanto a las visiones que destacan la homogeneidad de la cultura cubana como a las interpretaciones que la ven solamente en función de su fragmentarismo y heterogeneidad (De donde son los cantantes, de Severo Sarduy).

${ }^{19}$ Miguel Barnet, Gallego (Madrid: Alfaguara, 1981), p. 123.

${ }^{20} \mathrm{Cf}$. el comentario de Julia A. Kushigian, «Transgresión de la autobiografía y el Bildungsroman en Hasta no verte Jesús mío», Revista Iberoamericana, núm. 140 (julio-septiembre 1987), pp. 668-677.

${ }^{21}$ M. Pierette Malcuzynski, «Polyphonic Theory and Contemporary Literary Practices», Studies in Twentieth Century Literature, vol. 9, núm. 1 (Fall, 1984), p. 78 (la traducción al español es mía). 
Mientras que muchas novelas modernas - también las cubanas- se basan en una organización narrativa aparentemente polifónica (multiperspectivismo, empleo del diálogo, eliminación de la omnisciencia autorial), la polifonía, en el sentido bajtiniano, puede darse también en un discurso autobiográfico mediatizado, siempre que se evite una cosificación del narrador o la reducción de su personalidad a la conciencia exclusiva del autor ${ }^{22}$. El éxito estético e ideológico de la Biografía de un cimarrón y el valor del Gallego consisten precisamente en haber preservado la identidad del entrevistado, mientras que en Canción de Rachel la voz de la protagonista está visiblemente manipulada para servir los objetivos autoriales (la crítica del sistema seudorrepublicano cubano, el desenmascaramiento del machismo y de la conciencia falsa de Rachel).

A pesar de su experimentación con la forma de la novela testimonial, Barnet permanece fiel a su entendimiento de la historia en cuanto fenómeno complejo y multilineal. En los discursos de Montejo, Rachel y Manuel Ruiz afloran los diferentes tiempos de la historia discernidos por Braudel en su «deconstrucción» de la historiografía tradicional. Junto a la historia de las relaciones casi inmutables del hombre con su ambiente (Montejo), aparece la «historia de ritmos sutiles» protagonizada por varios grupos sociales (los negros, las mujeres, los inmigrantes gallegos) y, finalmente, la secuencia de eventos históricos (la Guerra de la Independencia, la guerra racial de 1912, los gobiernos republicanos, el impacto de la guerra civil española, etc.). El proyecto de reescribir el pasado cubano desde la perspectiva de los marginados le permite a Barnet demostrar la pluralidad de los tiempos sociales e individuales que integran la historia de larga duración y están moldeando la identidad colectiva.

\section{LA VIDA REAL: INTEGRACIÓN Y DESGARRAMIENTO CULTURAL}

Considerada en su integridad, la obra de Barnet presenta una visión dinámica de la cultura cubana en cuanto proceso de integración de diferentes fuerzas sociales y culturales. En los casos de Montejo y Rachel, la búsqueda de un modus vivendi se ve como sumamente conflictiva debido a las desigualdades sociales y los prejuicios sexuales y raciales de la sociedad prerrevolucionaria cubana. La integración de Manuel a la cultura isleña — aunque larga y dolorosa—se cumple, ya después de la revolución, en la figura de su hija mulata, cuyo nombre (América) es evidentemente simbólico. La visión de la cultura en cuanto juego de tendencias unificado-

\footnotetext{
${ }^{22}$ Ibid.
} 
ras y fuerzas centrífugas aparece también en la novela más reciente, $L a$ vida real (1986), donde se plasma «el sentimiento de dolor y de insatisfacción del emigrado cubano en tierras del Norte» ${ }^{23}$. Además de ofrecer el primer cuadro literario-testimonial de la emigración cubana de las décadas del cuarenta y cincuenta, Barnet ha captado, en el destino de Julián Mesa, el dramático desgarramiento entre dos culturas, dos lenguas, dos identidades que muchos de sus compatriotas están sufriendo también en la década de los ochenta. En este sentido, La vida real es una obra muy contemporánea y, según ha notado el mismo autor, «entraña un significado común en términos de destino histórico» ${ }^{24}$.

El acercamiento mutuo de la poesía, novela y etnografía constituye un rasgo original de la escritura barnetiana, pero los efectos de tal experimentación han variado de novela en novela. En La vida real, Barnet ha llegado, quizá, a una saturación de la fórmula testimonial, repitiendo básicamente el método del Gallego, donde el narrador es una síntesis literaria de varios informantes. Quizá la distinción entre la novela-testimonio (Biografía), la novela autorial de intención testimonial (Canción de Rachel) y la novela testimonial (Gallego, La vida real) permitirá diferenciar los distintos matices del testimonio barnetiano. A pesar de esta variedad de medios expresivos, la creación del cubano ostenta características de un proyecto homogéneo, cuyos objetivos constantes han sido y siguen siendo: la autoexplotación histórica del pueblo cubano, el autoanálisis existencial de sus representantes marginados y su autoexpresión a través del lenguaje conversacional y espontáneo.

${ }_{23}$ Miguel Barnet, La vida real (La Habana: Letras Cubanas, 1986), p. 5.

${ }^{24}$ La vida real, p. 6. 